[Stevens, K. (1993). Technology, Vocational Education and the New Zealand Economy: A Review of Recent Developments. New Zealand Annual Review of Education, 2, 167-178]

\section{Technology, Vocational Education and the New Zealand Economy: A Review of Recent Developments}

\section{KEN STEVENS}

$\mathrm{G}$ overnment responses to technological change through modifications to vocational education are usually designed to positively influence New Zealand's economic growth. Accordingly, polytechnics and universities, senior secondary schools and industry are increasingly being encouraged to work closely together. Recently, advances in information technology have made the interrelationship of technological change, vocational education and economic growth increasingly interdependent.

Over the past two years four aspects of the relationship between technological change and voca tional education have become prominent in New Zealand:

- a growing relationship between educational qualifications and employment;

- increased Government awareness of the place of science and technological education in the country's economic development;

- new communication technologies are being advocated for the delivery of vocational education; and

- the continued publicising of the potential contribution of vocational education to national economic growth

\section{Educational Qualifications and Employment}

The relationship between educational qualifications and employment is of considerable interest to parents, students, employers, vocational educators and the New Zealand Government. For some years ACCESS training, begun in 1987 as a "labour market training programme that

\section{Ken Stevens}

aimed to improve the job prospects of unemployed people, especially those who were disadvantaged in the labour market and for whom traditional training methods were unsuitable or unavailable" (Dominick, 1992 , p. 9) has had a prominent place in the country's polytechnics. The Education and Training Support Agency in 1992 noted, in a summary of the effectiveness of ACCESS training that, overall, ACCESS training was "effective in improving the labour market prospects of individuals". The factors that particularly influenced the employment outcomes of those who undertook these courses were recently found (Dominick, 1992) to be:

- attendance at work-based or vocational training;

- active job search behaviour;

- previous work experience;

- higher levels of education; and

- European ethnicity.

Where these factors were present, "high employment outcomes were achieved" and "reduced outcomes" were achieved where they were low or missing.

The report found that those who were most likely to benefit from ACCESS training were people: who were "on the margins of the labour market". They comprised those:

- who had lower educational qualifications;

- who were Maori;

- who had been unemployed for about a year; and

- who had little work experience.

The report noted that where all of these characteristics were present low levels of employment outcomes were achieved and in these cases a fourteen week ACCESS course was not sufficient to improve labour market prospects. Overall, Maori job seekers were found to be particularly disadvantaged. Within the ACCESS population, Maori were more likely than other groups in New Zealand to be without educational qualifications. This is a matter of national concern and deserves further investigation.

ACCESS training was found to be most effective for courses that were of a vocational rather than a "life skills" orientation. Vocational training, which made up the bulk of ACCESS courses, was found to lead to improved employment prospects for most individuals. However, 
vocational courses that were work-based were found to be particularly effective in improving employment outcomes (ibid, pp. 4-5).

The successor to ACCESS, the Training Opportunities Programme (TOP), aims to assist the most disadvantaged groups in the labour market. The TOP programme is intended to provide a number of linked courses towards a qualification rather than "one off" courses. In doing this it is intended to allow trainees progressively to develop their skills for the employment market.

In evaluating ACCESS training Dominick concluded that the scheme had been effective in improving the employment prospects of most individuals. Four fifths of the jobs that were obtained by ACCESS graduates were of more than thirty hours each week. The creation of the TOP programme will, hopefully, meet the needs of those students who have not benefited from the ACCESS programme. In creating the Training Opportunity Programme the Government has targeted a particularly disadvantaged group in New Zealand society and is seeking to provide both life skills and vocational opportunities for the long term unemployed who have few or no educational qualifications and limited work experience. The success of the initiative will be judged in future on the extent to which graduates from this group are able to participate in the workforce and contribute to the economy.

\section{The Place of Science and Technological Education}

The publication of Charting the Course: Report of the Ministerial Task Group Reviewing Science and Technology Education in February 1992 provided New Zealanders with an analysis of the state of science and technology in their education system. The task force was required to identify current and future skills and knowledge required in the workplace that were underpinned by science and technology; to identify any gaps, omissions and problems which prevented science and technology education from pre-school to tertiary level; to make recommendations on all aspects of science and technology education; and to outline areas in which initiatives sought by the Minister of Education in this area of the curriculum could be supported.

The report recommended that more attention be given to computing and information technology, to "practical and commercial" skills and to developing broader personal and communication abilities. It further noted the "current over emphasis on the theoretical aspects of science and technology education" in New Zealand schools together with insufficient attention to providing young people with the skills needed to adapt and contribute to changing workplace requirements. The authors of Charting the Course noted that the New Zealand public has a poor understanding of science and technology together with generally negative views of these areas of the curriculum. Investment in scientific research is not looked on favourably in New Zealand and the report pointed out that because of the absence of a career structure in science in this country at the present time there may, in future, be a shortage of scientists and technologists.

Considerably more attention was given to scientific than to technological education in the report. Charting the Course pointed out that science education should be suitable for all students to the end of form five, after which more specialised courses should be available for those planning scientific and technological careers. This has actually been the case for many years in New Zealand schools but, significantly, the report further recommended that general courses in science should be available at higher than fifth form level for those students who want "second chance" or non-career education in this aspect of the curriculum.

The report supported the Minister of Education's recommendation that technology be introduced in New Zealand schools as a compulsory, core part of the curriculum up to the end of form five. Information technology education was seen as being particularly important in the development of technological literacy, awareness and understanding. The Task Group pointed out that participation in science by Maori and Pacific Island people is low and recommended more input in resourcing and content decisions in this part of the curriculum by these groups. It was further pointed out that girls and women do not participate in science and technology courses to the extent that male students do. The below average participation in science and technology courses by females, Maori and Pacific Island groups requires further investigation if the policies that have been outlined are to be successful. The authors of the report nevertheless recommended that curriculum statements be written and that full implementation of technology education be available throughout the country by 1995 . A major problem in realising this new curriculum goal, however, will be the provision of adequate preparation of teachers of technology in the meantime.

The University of Waikato's Centre for Science and Mathematics Education Research published a paper in response to Charting the Course 
(Jones and Carr, 1992) which outlined teachers' perceptions of technology education. The broad aim of the Waikato research was to investigate ways of developing the technological capability of students "through problem-solving activities in contexts relevant to the learners". Jones and Carr looked at primary and secondary teacher perceptions of technology education to find out how this new area of the curriculum was interpreted in the schools.

Secondary teachers perceived technology in a variety of ways: science teachers who were interviewed saw technology education in the light of its application to science and as something extra in terms of conceptual development of this part of the curriculum; social studies teachers emphasised the social aspects of technology and wanted students to develop skills to cope with future technological changes; English teachers associated technology education with media studies, particularly with techniques used in journalism and drama while economics teachers considered technology in relation to resources. Those secondary teachers who taught technical subjects were found to have a broad view of what technology was about and "emphasised a "design and make" approach to using a variety of skills to realise practical outcomes The report found that many secondary teachers felt that given their current perceptions of technology education, they were already incorporating technology into their own subjects. Many secondary school teachers did not want to change what they were already doing and noted the difficulty of working with other departments in their schools in implementing this new curriculum initiative.

Primary teachers were not "locked into subject sub-cultures" like their secondary counterparts, but tended to view technology in schools largely in terms of computers, which many were trying to integrate into their classrooms. Just as computers can be used in classrooms to solve problems, technology education was seen by many primary teachers as being about finding out how things work. Many primary teachers saw technology education as being closely related to science education as well as to the study of social change.

Jones and Carr found that teacher perceptions of technology were largely influenced by their past experiences both in and out of schools. Those who had worked outside teaching tended to focus more on the "high tech" aspects of technology and in the case of manual teachers, the emphasis on technology was usually related to notions of construction. The report found that there was a wide range of perceptions of technology by New Zealand primary and secondary teachers. No teacher was found to have a broad view of technology incorporating technological knowledge and understanding, technological awareness and technological capability, all of which the authors of the report thought necessary for an adequate understanding of what technological education should be about. Jones and Carr concluded that if technology is to be successfully introduced in New Zealand schools, the subjective realities of teachers will have to be taken into account and that teachers and curriculum developers will have to work closely together.

\section{Communication Technologies and Vocational Education}

Increasingly, new communication technologies are being seen to have a place in the vocational education of New Zealanders. Over the last two years there have been several significant reports published in this country that suggest that some form of distance education may in future be the link between education, industry and the economy. A report by Buckrell et al. (1992), The Use of Telecommunications Technologies for the Enhancement of Educational Services, noted that "New Zealand's future becomes more and more a race between education and economic stagnation and social dislocation". The authors advocated the building of a "learning culture" to ensure New Zealand's "success as a nation", but the problem is how to do this within the resources that are available. The report contained a number of recommendations concerning the use of telecommunications in education and training, which, if adopted by Government, could open up new possibilities for New Zealanders and for their economy.

The approach advocated in the report was for "more and better use to be made of distance education and for the concepts of open learning to be accepted and implemented." Open learning, the authors pointed out, is "more an approach to education than a particular technique. Its aim is to make education more accessible to those who have been excluded from conventional forms of education". Distance education, as the term implies, "takes place where the learner is remote from the teacher in the teaching-learning process". To a large extent, however, the two concepts overlap.

In advocating the development of a "learning culture", the authors cautioned that it is also necessary to research the needs of employers 
and that to train for employment and economic success requires a "stringent focus on the results of training".

In the past such low level distance education technologies as print and mail have worked well; now the use of information technology (computers and communication) is changing the nature of distance education and tele-learning is becoming the core of this approach to teaching and learning. Massey University has begun supplementing teaching by sending computer discs through the mail to students and has made a commitment to establishing a national E-mail system in the near future. The Department of Communications at Victoria University has completed a tri-centre project through which students were linked from three sites in the Wellington region using audio-graphic conferencing and a shared electronic whiteboard. These projects use new communication technologies to teach students and, in doing so, promote co-operation between institutions. There is a growing realisation world-wide by distance educators that to be effective, communications technologies should be interactive or, if not, used in association with interactive techniques. Massey and Victoria Universities are pioneering new ways of using communication technologies in the delivery of courses and the possibility exists at Victoria of networking beyond the Wellington region to institutions overseas. A pilot project to realise this aim has recently been initiated. Buckrell et al. outlined two options for education providers:

- They can pursue their own individual paths with unilateral and competitive responses to rapid changes brought about by technological advances. Currently education providers tend to struggle individually, trying to survive in an increasingly competitive environment, not only nationally, but internationally.

- They can seek to collaborate with one another to exploit the potential of technology for optimum effectiveness at the national level.

The report further pointed out that there needs to be co-operation with technology providers. The major recommendations of the report were:

- That immediate consideration be given to reviewing the funding of distance and open learning to ensure that access to appropriate technology is gained by New Zealanders;
- That where resources can be made available now they be directed in the first instance towards training instructional designers and teachers in the use of new communications technologies;

- That greater use of New Zealand's existing television and telephone services for the delivery of educational services be developed;

- That Government monitor closely developments in the telecommunications market to ensure that education providers have access to a "truly contestable telecommunications network market within a reasonable timeframe";

- That market research be conducted to establish the unmet need for education and to establish the current picture of the use of telecommunications technologies for workplace and vocational training in New Zealand and the potential to improve it.

An increasingly significant national organisation is the Distance Education Association of New Zealand (DEANZ). From the 1991 and 1992 DEANZ annual conferences several papers were published which indicate that some of the recommendations by Buckrell et al. are appropriate to the enhancement of distance education provision in this country. Recent papers presented at DEANZ conferences indicate that communication technologies are increasingly being seen as appropriate by this country's distance educators. Richard Gan and John Hart presented papers on "Upgrading New Zealand's competitive advantage through education" and on "Computer-created virtual environments" respectively (Stevens, 1991, Vol. 2). In the annual proceedings of the Distance Education Association of New Zealand in 1992 however, it was noticeable that the majority of technologically-oriented papers on distance education were written by overseas contributors, most of whom came from Australia. These papers described new technological developments in distance education in that country, not in New Zealand.

The Relationship Between Vocational Education and Economic Growth

There have been several recent publications on the relationship between vocational education and economic growth: Broadfoot, 1992; Crocombe et al., 1991; McKay, 1991; Hawke, 1991; Winsley, 1991. The most publicised of these was the "Porter Report" (Crocombe et al., 1991) which provided an overview of New Zealand's economic performance 
and the determinants of the country's "national competitive advantage". This is an economic rather than an educational analysis. In economic terms the report noted that New Zealand had "not invested aggressively in human resource skills needed to be internationally competitive" and that "the rate of participation in the workforce is low as are the levels of training and skills. Most economically active people have emigrated, particularly to Australia. The education system is not well designed to develop economically useful skills".

The authors of the report further pointed out that New Zealanders, on average, spend less time in formal education than their counterparts in most industrialised nations. This is reflected in the New Zealand workforce of which over $38 \%$ have no formal educational qualifications. The dismal picture of this country's economic performance by Crocombe, Enright and Porter is in part attributed to the lack of education of the New Zealand population, a matter that has been raised by a variety of reports and research in the recent past (Bubendorfer, 1985; Beattie, 1986; Stevens, 1988).

The New Zealand Planning Council in 1991 brought together a variety of perspectives of the type of education that was appropriate to bring New Zealand education and industry into partnership, in one of its last publications, Curriculum: Core or Corset? One expatriate contributor with recent experience of British school-industry links (Mackay, 1991) noted that "schools need to encourage and value those areas of the curriculum which are not traditionally academic but which have potential for personal enterprise". Schools are increasingly faced with the issue of responding appropriately to the "enterprise culture" with its emphasis on personal skills such as self reliance, self confidence, decision making and risk taking.

A significant recent addition to the debate on the relationship of education to employment in New Zealand was the 1991 series of lectures by Sir Christopher Ball from the United Kingdom which were published with New Zealand responses by the Institute of Policy Studies (Hawke, 1991). In a summary of Sir Christopher Ball's lectures and the New Zealand responses to them, Hawke delineated several dimensions of the future of education and employment: participation in education, the nature of the curriculum, the funding of education and the relationship between management and culture.

Hawke noted a paradox in participation in education in $\mathrm{New}$ Zealand: while many people expressed dissatisfaction with the educational services available, they want more of them. Hawke pointed out that it is first necessary to define the population that is to be served by post-compulsory education and argued that it is not sufficient to do so solely on the basis of academic merit, a point of view with which Hood (1992) is in agreement. By making post-compulsory education available to all who want it in New Zealand, Hawke further pointed out, "requires reinforcement rather than revision of the commitment to lifelong learning which has developed over the last twenty years or so."

Hawke was in agreement with Sir Christopher Ball in saying that "post-compulsory education is no longer about selecting an elite for tasks which require cognitive skills and knowledge. Educationalists therefore have a duty to define what are reasonable expectations from any course of learning".

Finally, Hawke referred to the tension between the requirements of governmental and educational institutions. Educational institutions want autonomy while governments want to be sure of a good return for public funding. This tension can be minimised "by ensuring that objectives are clear and that funding mechanisms secure as large an overlap as possible between the desires of educationalists and what society wants from educational services. That is, educational institutions, working within their own judgement of what constitutes good educational practices, should be rewarded for providing what society wants".

The relationship between vocational education and economic growth that has been noted by Crocombe et al. (1991) has now become a prominent issue in New Zealand education. Government reports and research publications have, since the publication of Key to Prosperity (Beattie et al., 1986), told New Zealanders the same story: investment in education, particularly education of a vocational nature, is linked to national economic growth and ultimately to prosperity. The challenge for successive New Zealand governments is to find appropriate ways of realising this goal.

\section{Technology, Vocational Education and the New Zealand Economy}

There is a large measure of agreement between the recent publications on technology, vocational education and the New Zealand economy that have been reviewed above. It is perhaps timely to remember that the problems facing New Zealanders as they seek to maintain their standard of living by adapting to changing economic structures are 
common to other western democracies at the present time. The lectures by Sir Christopher Ball that had such impact in this country did so because the author could speak from his experience in a country that has also had to consider its national competitiveness and the appropriateness of its vocational education structures as it prepared to enter the European community. Just as Britain and the other European members of the community each look at the performance of their own systems of education in relation to their economies, so too does the United States, Canada and Japan. It would be an unusually complacent government at the present time that did not look critically at its educational system in relation to its economy. Such national selfanalysis is likely to intensify in future as new communication technologies enable vocational educators to cross state boundaries and both access and deliver courses internationally. Vocational education, like technology, will increasingly become international as new communication technologies are applied to enhance courses. Economies that prosper in future are not likely to be those that are nationally oriented but those which can provide internationally accepted technologies, backed by appropriate internationally-oriented systems of vocational education. By considering each of the four relationships between technological change and vocational education that have been outlined above, New Zealand has begun the process of moving from a national to an international vocational education orientation.

\section{References}

Beattie, D. et al. Key To Prosperity - Science and Technology. Wellington, Report of the Ministerial Working Party, 1986.

Broadfoot, P. "Changing Patterns of Assessment: An International Reform Agenda", Paper presented at the NZQA conference, Education for the twenty-first century, Wellington, 1992.

Bubendorfer, R. W. F. "Training an Appropriate Workforce for New Zealand" (mimeo) 1985.

Buckrell, B., Hamilton-Williams, R., McAulay K., Prebble, T. and Rajasingham, L. Report on the Use of Telecommunications Technologies for the Enhancement of Educational Services for the Department of the Prime Minister and Cabinet. Wellington, Consultel Associates Limited, 1992.

Charting the Course: Report of the Ministerial Task Group Reviewing Science and Technology Education. Wellington, Ministry of Research, Science and Technology and the Ministry of Education, 1992.

Crocombe, G. T., Enright, M. J. and Porter, M. E. Upgrading New Zealand's Competitive Advantage. Auckland: Oxford University Press, 1991.
Curriculum: Core or Corset? Community and Business Views. Wellington: New Zealand Planning Council, 1991.

Distance Education Association of New Zealand, Distance Education: Quality and Equality. Dunedin, DEANZ, 1992.

Dominick, C. The Effectiveness of Access Training. Wellington: Education Training and Support Agency, 1992.

Gan, R. "Upgrading New Zealand's Competitive Advantage through Education" in Stevens, K. J. (ed) The Learner: Management, Technology and Future Directions in Distance Education in New Zealand, Vol. 2. Wellington, DEANZ, 1991.

Hart, J. "Learning in Cyberspace - Experiential Education in a ComputerCreated Virtual Environment" in Stevens, K. J. (ed) The Learner: Management, Technology and Future Directions in Distance Education in New Zealand. Vol. 2, Wellington, DEANZ, 1991.

Hawke, G. R. (ed) Sharks and Splashes - The Future of Education and Employment. Wellington: Institute of Policy Studies, Victoria University of Wellington, 1991.

Hood, D. "Education and Qualifications: The Challenge for the Future", paper presented at the Qualifications for the Twenty-first Century Conference, Wellington, 1992.

Jones, A. and Carr, M. Teachers' Perceptions of Technology Education. Hamilton: Centre for Science and Mathematics Education Research, University of Waikato, 1992.

Mackay, F. "Education and Industry in Partnership" in Curriculum: Core or Corset? Wellington: New Zealand Planning Council, 1991.

Stevens, K. J. "Science, Technology and the Re-organisation of New Zealand Education" in Hattie, J., Kefford, R. and Porter, P. (eds) Skills, Technology and Management in Education. Deakin, Canberra: The Australian College of Education, 1988

Stevens, K. J. (ed) The Learner: Management, Technology and Future Directions in Distance Education in New Zealand. Wellington: Proceedings of the Distance Education Association of New Zealand, Vol. Two, 1991.

Winsley, P. Technological Change and Employment. Wellington: Foundation for Research, Science and Technology, 1991.

\section{The author}

Ken Stevens is a Senior Lecturer in Education at Victoria University of Wellington. His research interests are in educational administration and the sociology of education, particularly rural, distance and vocational education. Recently he reviewed distance education networks in Australia, Papua New Guinea and the South Pacific with the assistance of a Claude McCarthy Fellowship. 